\title{
The association between daily average feeding behaviors and morbidity in automatically fed group-housed preweaned dairy calves
}

\author{
W. A. Knauer, ${ }^{* 1}$ S. M. Godden, ${ }^{*}$ A. Dietrich, $†$ and R. E. James $†$ \\ *Department of Veterinary Population Medicine, University of Minnesota, St. Paul 55108 \\ †Department of Dairy Science, The Virginia Polytechnic and State University, Blacksburg 24061
}

\begin{abstract}
Group housing and computerized feeding of preweaned dairy calves is gaining popularity among dairy producers worldwide, yet disease incidence and detection remain a challenge in these systems. The aim of this prospective observational cohort study was to describe the relationship between morbidity and feeding behavior around the period of illness detection. Calves were enrolled upon entrance to the group pen on 10 farms in Minnesota $(\mathrm{n}=4)$ and Virginia $(\mathrm{n}=6)$ utilizing group housing and computerized feeding from February until October 2014. Morbidity and mortality events were recorded by the calf caregiver. Farms were visited either every week (Minnesota) or every other week (Virginia) to collect calf enrollment data, feeding behavior data, and health records. Daily average feeding behaviors (drinking speed, $\mathrm{mL} / \mathrm{min}$; daily consumption, $\mathrm{L} / \mathrm{d}$; rewarded visits to the feeder; and unrewarded visits to the feeder) were described both overall and for sick and healthy calf days. Multivariable mixed models were built to assess the differences in daily average feeding behaviors (drinking speed, daily consumption, rewarded visits, unrewarded visits) between matched sick and healthy calves around the time of an illness event ( -10 to $10 \mathrm{~d})$. Final models were controlled for calf age, region (Minnesota and Virginia), group size, disease diagnosis, the random effect of farm, and repeated measurements on calf. A stratified analysis was performed by both day from treatment event and disease diagnosis. We enrolled 1,052 calves representing 43,607 calf days over 9 mo. From these, 176 sick calves had a matched control and were carried forward to the matched pair analysis. Fifty-five percent of sick calves $(97 / 176)$ were treated for diarrhea, $30 \%$ (53/176) were treated for pneumonia, and 15\% (26/176) were treated for ill thrift. Sick calves drank $183 \pm 27 \mathrm{~mL} /$ min (mean
\end{abstract}

Received November 29, 2016.

Accepted March 13, 2017.

${ }^{1}$ Corresponding author: knaue020@umn.edu \pm standard error) more slowly, drank $1.2 \pm 0.6 \mathrm{~L} / \mathrm{d}$ less, and had $3.1 \pm 0.7$ fewer unrewarded visits than control calves on the first day of treatment. These differences began up to $4 \mathrm{~d}$ before the calf was detected as sick, and persisted for 7 to $10 \mathrm{~d}$ after treatment. However, changes in feeding behaviors varied by disease diagnosed. Rewarded visits were not associated with morbidity status. The results of this study indicate that sick calves change their feeding behavior before and during an illness event, suggesting that feeding behavior may be a useful tool to detect disease onset.

Key words: group housing, feeding behavior, calf health

\section{INTRODUCTION}

Group housing of preweaned dairy calves has recently increased in popularity among dairy producers, with an estimated $15 \%$ of farms in the United States housing calves in groups (USDA-NAHMS, 2016). Automatic, or computerized, feeding is one method of delivering milk to group-housed calves. This management strategy has the benefits of facilitating the ability to feed more milk per day (Huuskonen and Khalili, 2008; Roth et al., 2008), reallocation of calf labor (Kung et al., 1997), and social benefits to the calf (Jensen et al., 1999; De Paula Vieira et al., 2012). However, calves housed in large groups ( $\geq 7$ calves) have an increased incidence of respiratory disease (Svensson et al., 2003; Svensson and Liberg, 2006) and mortality (Losinger and Heinrichs, 1997) compared with calves housed in small groups. In addition, it can be more difficult to detect diseased calves in group housing systems (Steenkamer, 1982). It has been well established that calf morbidity is associated with impaired future performance, including reduced rate of gain, increased culling risk, increased age at first calving, and reduced milk yield (Waltner-Toews et al., 1986; Correa et al., 1988; Virtala et al., 1996; Heinrichs and Heinrichs, 2011). Therefore, understanding how sick calves behave in a group is an important first step to determine management strategies and tools that can improve disease detection and intervention. 
Regardless of housing strategy, the 2 most prevalent causes of morbidity and mortality during the preweaning period are diarrhea and respiratory disease, accounting for 21.3 and $12 \%$ of morbidity and 55.9 and $26.2 \%$ of mortality, respectively (USDA-NAHMS, 2016). Infectious and inflammatory processes induce physiological and behavioral changes (Johnson, 2002), including fever, anorexia, lethargy, depression, social isolation, and a reduction in grooming behavior (Hart, 1988), and these adaptive responses have been shown to be important for survival (Kluger and Vaughn, 1978; Murray and Murray, 1979). Infectious disease induction models have been shown to decrease TMR intake in heifers (Steiger et al., 1999) and decrease rumination time, hay intake, self-grooming behavior, and increase the duration of lying behavior in dairy calves (Borderas et al., 2008). Recent work has shown that group-housed calves that have respiratory disease, a fever, or are recovering from diarrheal disease are half as likely to approach a novel object or human as compared with healthy pen mates (Cramer and Stanton, 2015). These studies indicate that calves change their behavior when ill, and suggest that feeding behavior may be a useful predictor and indicator of disease onset.

One potential advantage of sophisticated computerized milk delivery systems over other (manual) milk delivery systems is that computer software can record and report individual calf feeding behaviors that may be useful for disease monitoring purposes. For example, a calf may be flagged by computer software as being a suspect for illness if it shows a deviation (reduction) in daily milk intake as compared with a rolling average. However, there is reason to believe that current algorithms used by computer feeding software lack in timeliness or sensitivity to detect disease events in some calves. For example, Borderas et al. (2009) reported that calves fed a high level $(\geq 12 \mathrm{~L} / \mathrm{d})$ of milk drank significantly less milk the day they were detected as sick by an observer as compared with healthy calves, but this behavior change only occurred on the same day as illness detection. Svensson and Jensen (2007) reported that sick calves had a reduction in visits to the feeder without milk (unrewarded), but found no difference in speed of milk consumption or visits to the feeder with a milk meal (rewarded). That work explored associations between health status and some but not all measureable feeding behaviors [i.e., drinking speed $(\mathrm{mL} / \mathrm{min})$, visits to the feeder with a milk meal, visits to the feeder without a milk meal, and total consumption $(\mathrm{L} / \mathrm{d})$ ]. However, these studies had a small sample size and smaller group sizes than are frequently observed in the United States ( 8 to 13 vs. 20 to 25 calves per group). To better understand how sick calves behave in a group pen, it is important to do large observational field studies, to capture a better understanding of both variation and the dynamic nature of these systems. The objective of the current study was to describe the relationship between feeding behaviors and morbidity around the time of an illness event. We hypothesized that calves experiencing a morbidity event would exhibit changes in feeding behaviors on the days leading up to and during the sickness event as compared with a matched healthy calf.

\section{MATERIALS AND METHODS}

\section{Herd Selection}

This prospective observational cohort study was conducted in a convenience sample of 10 commercial dairy herds; 4 herds in Minnesota and 6 herds in Virginia. Herds were selected based on their use of a sophisticated calf feeding system (Forster-Technik, Engen, Germany) and must have had the system in place for greater than 1 yr. Herds also must have provided a peak daily milk allowance of $\geq 7 \mathrm{~L}$ per day at a TS level $>125 \mathrm{~g} / \mathrm{L}$ (grams of milk powder added to $1 \mathrm{~L}$ of water).

\section{Calf Management and Data Collection}

The use of animals in the study was approved by the University of Minnesota Institutional Animal Care and Use Committee (\#1308-30844A). Data collection occurred from February 2014 to October 2014. An initial questionnaire was used to describe calf facilities and general calf management. Heifer and bull calves were enrolled into the study when they entered the group pen, and exited the study when they were weaned from the automatic feeder. For each calf entering a group pen, the calf manager recorded the calf id, breed, sex, birth date, and pen entry date. Sick calves were identified based on daily subjective evaluations by the calf manager, and the date, time, treatment, and disease treated were recorded for each morbidity event. Mortality events were recorded similarly. We attempted to standardize case definitions across farms through training and use of a visual scoring system that evaluates ocular and nasal discharge, cough, head tilt, fecal score, and general attitude (McGuirk, 2008).

A study technician visited the farm each week (Minnesota) or biweekly (Virginia), to collect calf enrollment data, treatment records, and mortality data. An 8-mL venous blood sample was collected from the jugular vein of a convenience sample of calves between $24 \mathrm{hr}$ to $7 \mathrm{~d}$ of age for serum total protein measurement $(\mathrm{g} / \mathrm{dL})$ with a digital serum refractometer (MISCO Palm Abbe 
model PA203X, MISCO, Cleveland, OH). Approximate birth (d 1-7 of life) and weaning (d 50-60 of life) weights were estimated in kilograms from a convenience sample of calves using a weight tape (Nasco, Fort Atkinson, WI). Day-level average feeding behavior data were collected through the automatic feeding software program (Kalb Manager, Förster-Technik) each week. Specific feeding behaviors recorded included: total milk intake (CON; L/d), average drinking speed (DS; mL/ min), and total number of rewarded (RV; visits to the feeder with a milk meal) and unrewarded (URV; visits to the feeder without a milk meal) visits to the feeder. Farm personnel were blinded to sensor-derived feeding behavior data throughout the study, beyond what was already being reported and used for animal monitoring by the on-farm software. The Kalb Manager software provides DS, daily consumption, and deviation data to the producer. The majority of calf caregivers used milk consumption $(\mathrm{n}=6)$ to screen calves, but none used the data from Kalb Manager as the sole trigger for calf diagnosis or treatment.

\section{Statistical Analysis}

Sample Size. We enrolled 1,052 calves on 10 farms in Minnesota (MN) and Virginia (VA). Sixty-three percent of calves had a first treatment event, resulting in 660 treated calves and 392 healthy calves. This sample size ( $>250$ calves per group) provided in excess of $80 \%$ power and $95 \%$ confidence to detect a 1 -L difference in daily milk intake (i.e., 8 vs. $7 \mathrm{~L} / \mathrm{d}$ ) between sick and healthy calves (assumed SD $=4 \mathrm{~L} / \mathrm{d}$, 1-tailed test).

Case Definitions. Disease diagnosis was based on visual assessment by the on-farm calf caregiver and attempts were made to standardize across farms based on use of a modified scoring system as defined by McGuirk (2008). A case of diarrhea (DIA) was defined as visible diarrhea (very loose or watery feces; fecal score of 2 or 3 on a 0 to 3 scale) and treatment with antibiotics, electrolytes, or IV fluids, or a combination of the 3. A case of respiratory (RESP) disease was defined as a calf with an increased respiratory rate or effort, cough, and treatment with antibiotics. A case of ill thrift (ILL) was defined as either (1) a calf that had a rectal temperature $>39.5^{\circ} \mathrm{C} ;(2)$ a calf that was depressed, but for which the caregiver did not have a clear diagnosis; or (3), a calf with other miscellaneous illnesses, such as umbilical infection, joint infection, and injury and treatment with antibiotics or nonsteroidal anti-inflammatories. Treatment events known to be prophylactic (i.e., antibiotic administered at pen entry), which occurred on 1 farm only, were excluded from analysis. Duration of treatment was defined as the period between the first and last treatment. A new treatment event was defined as an event that occurred for the first time, an event that occurred at least $5 \mathrm{~d}$ after conclusion of treatment for a previous event, or an event that occurred within $5 \mathrm{~d}$ of the conclusion of a previous event but represented a separate disease diagnosis.

Producer-Reported Treatment Validation. To address concerns over the use of producer reported treatment data to represent true disease diagnosis, a validation study was performed on $4 \mathrm{MN}$ farms in $\mathrm{Au}-$ gust 2015. All farms were visited once and a trained veterinarian walked all pens and identified calves to be screened for illness detection using the modified calf health-scoring system (McGuirk, 2008). This list was then compared with the calves that the herd supervisor had identified to screen or treat on the same day. The veterinarian was the reference standard. A positive test was a calf that was screened or treated on the test day. A negative test was a calf that was in the group pen but was not identified as needing an intervention. Diagnostic test characteristics were calculated from a 2 $\times 2$ table (Dohoo et al., 2009).

Descriptive Statistics. All statistical analyses and modeling were performed in SAS (v.9.4; SAS Institute, Cary, NC). Calves already in the pen when the study began, calves with fewer than $10 \mathrm{~d}$ of feeder data (excluding mortalities), and calves that had substantial missing data ( $>10 \mathrm{~d}$ in the pen) were excluded from analysis. Descriptive statistics (mean, median, SD, range) were generated to describe general calf management overall and to describe for calves overall: (1) general calf characteristics (e.g., age at entry and exit from pen, group size, days in pen); (2) calf health data according to farm personnel (e.g., disease treated, days treated, days of age at treatment, days in pen at treatment, number of treatments, proportion treated by disease and treatment event); and (3) feeding behavior data (e.g., DS, CON, URV, RV) both overall, by feeding period (ramp up phase, where calves are gradually increased in milk; hold phase, where calves are held at a peak allowance; and ramp down, where the daily milk allowance is reduced until calves are completely weaned from the auto-feeder), and for sick (treated) and healthy calf (not treated) days. Histograms for outcome variables were generated to check for normality. Correlations between linear predictors of interest were assessed to check for collinearity.

Matched Pair Analysis. A matched pair design was used to determine the difference in feeding behaviors (DS, CON, RV, URV) between sick and healthy calves. Feeding behaviors during the entire milk-fed period were evaluated, excluding the weaned period. 
Cases were defined as a calf that had a first treatment event during the time that they were in the group pen. Control calves were matched by age $( \pm 7 \mathrm{~d})$, pen, breed, and sex, and were defined as a calf that did not have a treatment event from birth until weaning. The first day of sickness diagnosis (by farm personnel) was designated as $\mathrm{d} 0$, and the $10 \mathrm{~d}$ before and after diagnosis were matched to the age-matched healthy control. A 20 -d window ( -10 to $10 \mathrm{~d}$ ) around the treatment event was chosen as the period of interest based on work by Quimby et al. (2001) and Schaeffer et al. (2004), who reported that behavioral signs of illness can occur 4 to $7 \mathrm{~d}$ before clinical signs are noticed. Case and control calves were matched on a 1:1 ratio. Treated calves that did not have a pen and age-matched untreated calf available to serve as the control were excluded from this analysis. Only first treatment events were considered in the analysis.

Univariable analyses were first performed to determine the relationship between feeding behavior (DS, CON, RV, URV; outcome variables) and the occurrence of a sickness event (treated; yes or no), as well as additional predictors of interest including region $(\mathrm{MN} /$ VA), farm, machine, pen, month of year, group size, age at pen entry, disease status before pen entry (treated before entrance to the group pen; yes or no), disease diagnosis (DIA, RESP, ILL), days in pen at disease diagnosis, calf breed, day relative to diagnosis of illness ( -10 to 10$)$, feeding period (ramp up, hold, ramp down), and stocking density $\left(\mathrm{m}^{2}\right.$ per calf). Predictors that were significant at the $P<0.20$ level in the univariable analysis were carried forward to offer to the multivariable analysis.

Multivariable generalized linear regression was used to describe the difference in each feeding behavior (DS, CON, RV, and URV; outcome variables) for matched healthy or sick calves (predictor) on the days before and during illness ( -10 to 10$)$. All other calf days in the group pen were excluded from analysis. Predictors with $P<0.20$ in the univariable models were initially offered to the full main effects model. A backward stepwise variable selection was used, with the least-significant variables being removed one by one until all predictors remaining had $P<0.05$. Farm was controlled for as a random effect and repeated measures by calf were accounted for. Final models were chosen based on lowest Akaike's information criteria. Interactions between biologically plausible main effects were explored. The effect of time was explored by evaluation of an interaction term that described the association between day relative to diagnosis of illness and feeding behavior (DS, CON, RV, and URV). Models were then stratified by both day from illness ( -10 to 10$)$ and disease status
(DIA, RESP, ILL) to explore the association between feeding behaviors and day from illness detection for different diseases treated. Final significance was determined at $P<0.05$.

\section{RESULTS}

\section{General Farm and Feeder Management Description}

Ten farms were enrolled in the study, 4 in $\mathrm{MN}$ and 6 in VA. Dairies had between 110 and 850 lactating dairy cows, and 1 enrolled farm was a custom heifer grower. All automatic calf feeders were Forster-Technik machines representing 6 Lely calf feeders (Lely Calm $\mathrm{n}=3$; Lely Calm Combi $\mathrm{n}=3$; Lely North America, Pella, IA), and 4 DeLaval calf feeders (DeLaval CF1000; DeLaval, Tumba, Sweden). Four farms had 2 feeders with 4 pens of calves, and 6 farms had 1 feeder and 2 pens of calves. Each pen of calves had 1 nipple feeding station. All farms managed calves in individual housing before introduction to the feeder, and introduced calves to the group pen between 1 and $12 \mathrm{~d}$ of age. The majority of farms managed their calf pens as dynamic groups $(\mathrm{n}=8)$ with 2 farms practicing all in/all out management. Pens were bedded with straw $(n=2)$, a combination of straw and sawdust $(\mathrm{n}=6)$, wood chips $(\mathrm{n}=1)$, or corn stalks and sand $(\mathrm{n}=1)$. Estimated average space per calf per pen across all farms was 7.4 $\pm 3.3 \mathrm{~m}^{2}$.

Two farms fed pasteurized whole milk with balancer (Land O'Lakes Milk Balancer, Land O'Lakes Animal Milk Products, Shoreview, MN) and the remaining farms fed milk replacer only (Blueprint 22-20 Dx, FormA-Feed Inc. Stewart, MN; Cow's Match ColdFront/ WarmFront, Land O'Lakes Animal Milk Products,; Maxi Balance Plus BVT BM, Purina Animal Nutrition, Shoreview, MN; 20/22WPL BOV-MOS DFB, Renaissance Nutrition, Roaring Spring, PA). The average ramp up period lasted $9.7 \mathrm{~d}$ (range $=3-18$ ), calves were held at their maximum feeding level for $29.9 \mathrm{~d}$ (range $=$ 18-41), and calves were ramped down and weaned over an average of $13 \mathrm{~d}$ (range $=2-42$ ). Average full feeding level offered was $9.4 \mathrm{~L} / \mathrm{d}$ (range $=7-16$ ), fed at a TS concentration of $155 \mathrm{~g} / \mathrm{L}($ range $=143-165)$.

\section{General Calf-Level Description}

We enrolled 1,304 calves between February 2 and October 16, 2014. Of these, 153 had greater than $10 \mathrm{~d}$ of missing data, and 99 had less than $10 \mathrm{~d}$ on the feeder; therefore, these animals were excluded, leaving 1,052 calves ( $\mathrm{n}=987$ heifers; $\mathrm{n}=65$ bulls $)$ to consider for analysis representing 43,607 calf days on the automatic 
Table 1. Descriptive calf level statistics of all enrolled calves, both overall and by matched pair analysis

\begin{tabular}{|c|c|c|c|c|c|c|}
\hline \multirow[b]{3}{*}{ Variable } & \multicolumn{2}{|c|}{$\begin{array}{l}\text { All enrolled calves } \\
\quad(\mathrm{n}=1,052)\end{array}$} & \multicolumn{4}{|c|}{$\begin{array}{l}\text { Matched pair calves } \\
\qquad(\mathrm{n}=352)\end{array}$} \\
\hline & \multirow[b]{2}{*}{$\mathrm{n}$} & \multirow[b]{2}{*}{ Mean $\pm \mathrm{SD}$} & \multicolumn{2}{|c|}{ Treated calves } & \multicolumn{2}{|c|}{ Control calves } \\
\hline & & & $\mathrm{n}$ & Mean \pm SD & $\mathrm{n}$ & Mean \pm SD \\
\hline Age at pen entry (d) & 1,052 & $9.1 \pm 5$ & 176 & $9.8 \pm 4.4$ & 176 & $9.9 \pm 4.4$ \\
\hline Wean age $(\mathrm{d})$ & 656 & $55.4 \pm 8.2$ & 115 & $57.2 \pm 14.5$ & 126 & $53.8 \pm 6.9$ \\
\hline Wean weight ${ }^{2}(\mathrm{~kg})$ & $\begin{array}{r}102 \\
72\end{array}$ & $79.0 \pm 11.3$ & 8 & $78.1 \pm 8.5$ & 16 & $81.8 \pm 11.0$ \\
\hline $\mathrm{ADG}(\mathrm{kg} / \mathrm{d})$ & & 0.72 & & 0.72 & & 0.76 \\
\hline
\end{tabular}

${ }^{1}$ Birth weight defined as a weight tape measurement taken from 1 to $7 \mathrm{~d}$ of life.

${ }^{2}$ Wean weight defined as a weight tape measurement taken from 50 to $60 \mathrm{~d}$ of life.

milk feeder. From the 1,052 eligible calves, 176 pairs (n $=352$ ) of calves were carried forward to the matched pair analysis, representing 5,984 calf days.

General calf-level descriptive statistics are reported as mean \pm standard deviation. For all enrolled calves $(\mathrm{n}=1,052)$ the age at calf entry to the pen was $9.1 \pm$ $5 \mathrm{~d}$ with a group size of $17 \pm 5$ calves per group. Not all calves had a weaning date reported $(\mathrm{n}=656)$, but those that did were weaned from milk at $55.4 \pm 8.2 \mathrm{~d}$ of age. Of the calves sampled, enrolled calves had an average serum total protein of $5.7 \pm 0.8 \mathrm{~g} / \mathrm{dL}$, a birth weight of $42.2 \pm 4.7 \mathrm{~kg}$, and a weight at weaning of 79.0 $\pm 11.3 \mathrm{~kg}$. Calves in this study gained an average of $0.72 \mathrm{~kg} / \mathrm{d}$. Both treated and control calves had numerically similar birth weights, but the treated calves were lighter at weaning than the control calves, and had a reduced ADG (Table 1 ).

\section{Morbidity and Mortality}

Of the 1,052 enrolled calves, $63 \%(660 / 1,052)$ experienced a first treatment event, $22 \%(232 / 1,052)$ a second treatment event, and $7 \%(77 / 1,052)$ were treated for a third time while in the group pen. Treatments were distributed evenly among days of the week (Sunday through Saturday). The most common first treatments were for diarrheal disease $(50 \% ; 331 / 660)$, respiratory disease $(19 \% ; 127 / 660)$, fever $(21 \% ; 137 / 660)$, and ill thrift $(8 \% ; 54 / 660)$. First treatments occurred at $9.3 \pm$ $8.5 \mathrm{~d}$ after introduction to the group pen, and calves diagnosed with illness were treated an average of 3.8 \pm 3.9 d duration. Farm personnel treated 151 enrolled calves before they entered the group pen during the period in individual pens or hutches. The mortality rate of enrolled calves during the group housing period was $1.14 \%$.

Of the 176 sick calves in the matched pair analysis, $55 \%(97 / 176)$ were treated for diarrheal disease, $30 \%$
$(53 / 176)$ were treated for respiratory disease, and $15 \%$ (26/176) were treated for ill thrift, including calves with a fever. Treatment for scours occurred at $7 \pm 5.1$ $\mathrm{d}$ in the group pen and lasted for $3.1 \pm 3.7 \mathrm{~d}$. Treatment for respiratory disease occurred at $14 \pm 10 \mathrm{~d}$ in the group pen and lasted for $2.6 \pm 3.3 \mathrm{~d}$, and treatment for ill-thrift occurred at $12 \pm 10 \mathrm{~d}$ in the group pen and lasted for $3.2 \pm 2 \mathrm{~d}$.

\section{Validation of Using Producer-Identified Treatment Events}

We evaluated 235 calves on $4 \mathrm{MN}$ farms. As compared with an experienced veterinarian (reference standard), the overall sensitivity, specificity, and accuracy of using the producer to determine the health status of a calf (sick or healthy) in a pen of group-housed preweaned calves were 26, 97, and $84 \%$ respectively. The kappa statistic was 0.31 , indicating fair agreement.

\section{Feeding Behaviors for All Calves}

Feeding behaviors (DS, CON, RV, and URV) were analyzed for 1,052 calves representing 43,607 calf days on the automatic feeder during the milk-fed period. Over the entire feeding period, all calves in our study drank milk at an average $( \pm \mathrm{SD})$ of $877 \pm 344 \mathrm{~mL} /$ min, averaged $6.6 \pm 2.2 \mathrm{~L}$ of milk consumed per day, visited the feeder an average of $4.3 \pm 2.9$ times with a milk meal, and visited the feeder an average of $7.2 \pm$ 7.7 times without a milk meal. All calves in the study increased their daily average DS and URV over the course of the feeding period. Daily average CON and RV increased from the ramp up to the hold period, and then decreased during the ramp down period. On the days they were treated, sick calves ( $\mathrm{n}=3,230$ calf days) had a numerically lower daily average drinking speed as compared with healthy calves $(\mathrm{n}=40,377$ calf days) as 
Table 2. Daily average feeding behaviors, both overall and for sick and healthy calf days, for calves housed in groups and fed automatically $($ mean $\pm \mathrm{SD})$

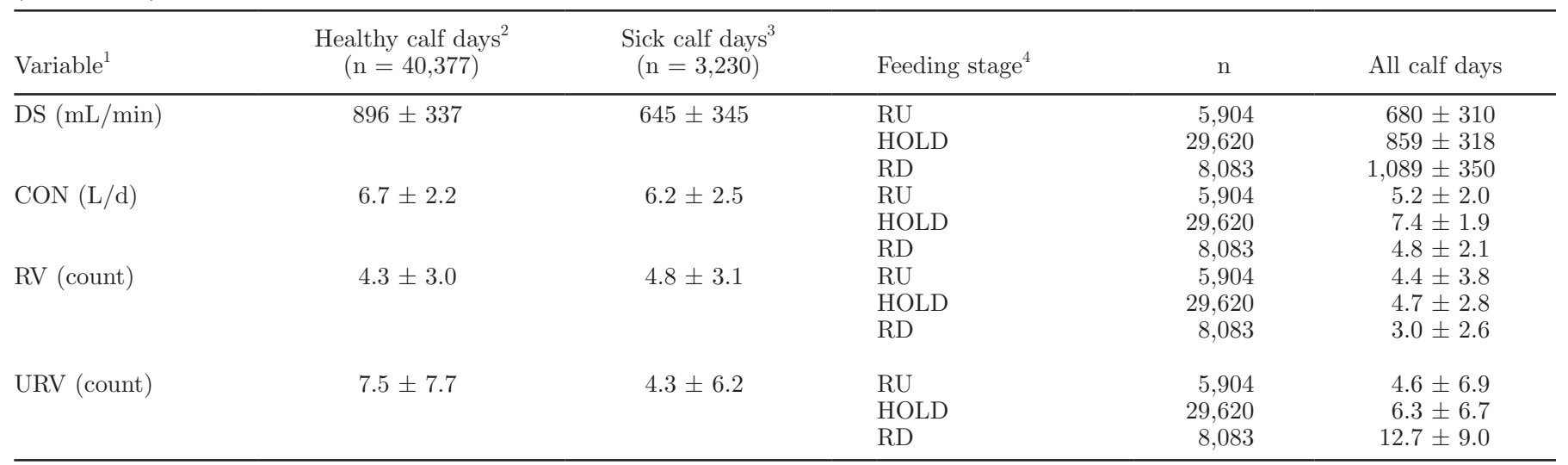

${ }^{1} \mathrm{DS}=$ drinking speed; CON = daily milk consumption $(\mathrm{L} / \mathrm{d}) ; \mathrm{RV}=$ rewarded visits to the milk feeder; URV = unrewarded visits to the feeder. ${ }^{2}$ Healthy calf days $=$ days in the group pen when the calf was not being treated for illness.

${ }^{3}$ Sick calf days $=$ days in the group pen when the calf was being actively treated for illness.

${ }^{4} \mathrm{RU}=$ ramp up on milk feeding level immediately after entrance to the group pen; HOLD = the maximum milk feeding level where the calf is held for 2 to $3 \mathrm{wk} ; \mathrm{RD}=$ ramp down on milk feeding level immediately before weaning.

well as fewer URV per day. Daily average CON and RV were not numerically different (Table 2).

\section{Matched Pair Analysis}

Drinking Speed. The final mixed model describing the association between DS and disease status over the $10 \mathrm{~d}$ surrounding a treatment event controlled for the effect of region, day from treatment event, month, calf age, diagnosis, the random effect of farm, and repeated measurements by calf. Over the $20 \mathrm{~d}$ surrounding a treatment event, sick calves drank an average of 88 $\pm 20 \mathrm{~mL} / \mathrm{min}(P<0.001)$ more slowly than matched healthy control calves. On the day of illness detection by a calf caregiver, sick calves drank an average of 183 $\pm 27 \mathrm{~mL} / \mathrm{min}(P<0.001)$ more slowly than matched healthy control calves. When considering all diseases, results of the day-stratified model showed a significant decrease in drinking speed $2 \mathrm{~d}$ before a treatment event, which persisted through the end of $10 \mathrm{~d}$ (Figure 1). However, after stratifying by disease type, it was noted that calves treated for RESP only drank significantly more slowly than their healthy controls on the day of illness detection. In contrast, calves treated for DIA drank significantly more slowly from $d-3$ to 10 . The ILL calves drank more slowly on the day of treatment, and this difference persisted until day +6 . (Figure 2)

Unrewarded Visits. During the time surrounding a treatment event, treated calves had $2.3 \pm 0.4$ fewer $(P<0.001)$ URV to the automatic feeder after controlling for the effect of calf age, group size, month, pair diagnosis, the random effect of farm, and repeated measurements by calf. When considering all diseases, results of the day stratified model showed a significant difference in URV between treated and healthy calves on days $-10,-9,-6$, and then from $d-4$ through the end of $\mathrm{d} 10$ post-treatment (Figure 3 ). On the day of treatment, sick calves had $3.1 \pm 0.7(P<0.001)$ fewer unrewarded visits to the feeder than matched healthy calves. However, after stratifying by disease type, calves treated for RESP only showed a significant difference on the day of treatment, ILL calves differed on $d-6$,

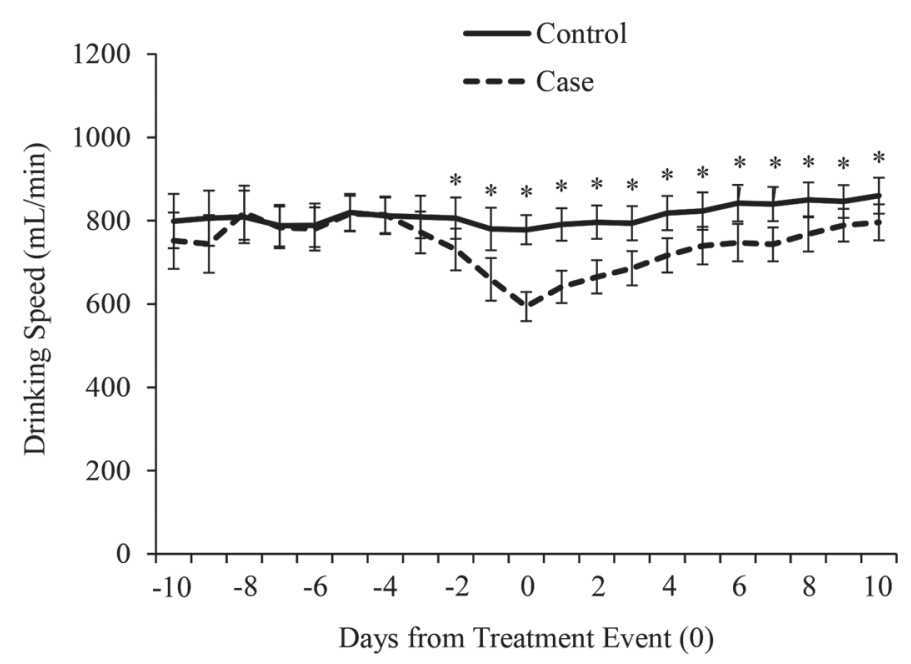

Figure 1. Results of a stratified mixed model explaining the relationship between morbidity (all diseases) and daily average drinking speed $(\mathrm{mL} / \mathrm{min})$ for matched pairs of sick (case; $\mathrm{n}=176)$ and healthy (control; $\mathrm{n}=176)$ calves. This model controlled for the effect of region, month, calf age, and disease treated and controlled for the random effect of farm. Reported are adjusted means and standard errors. ${ }^{*} P$ $<0.05$. 

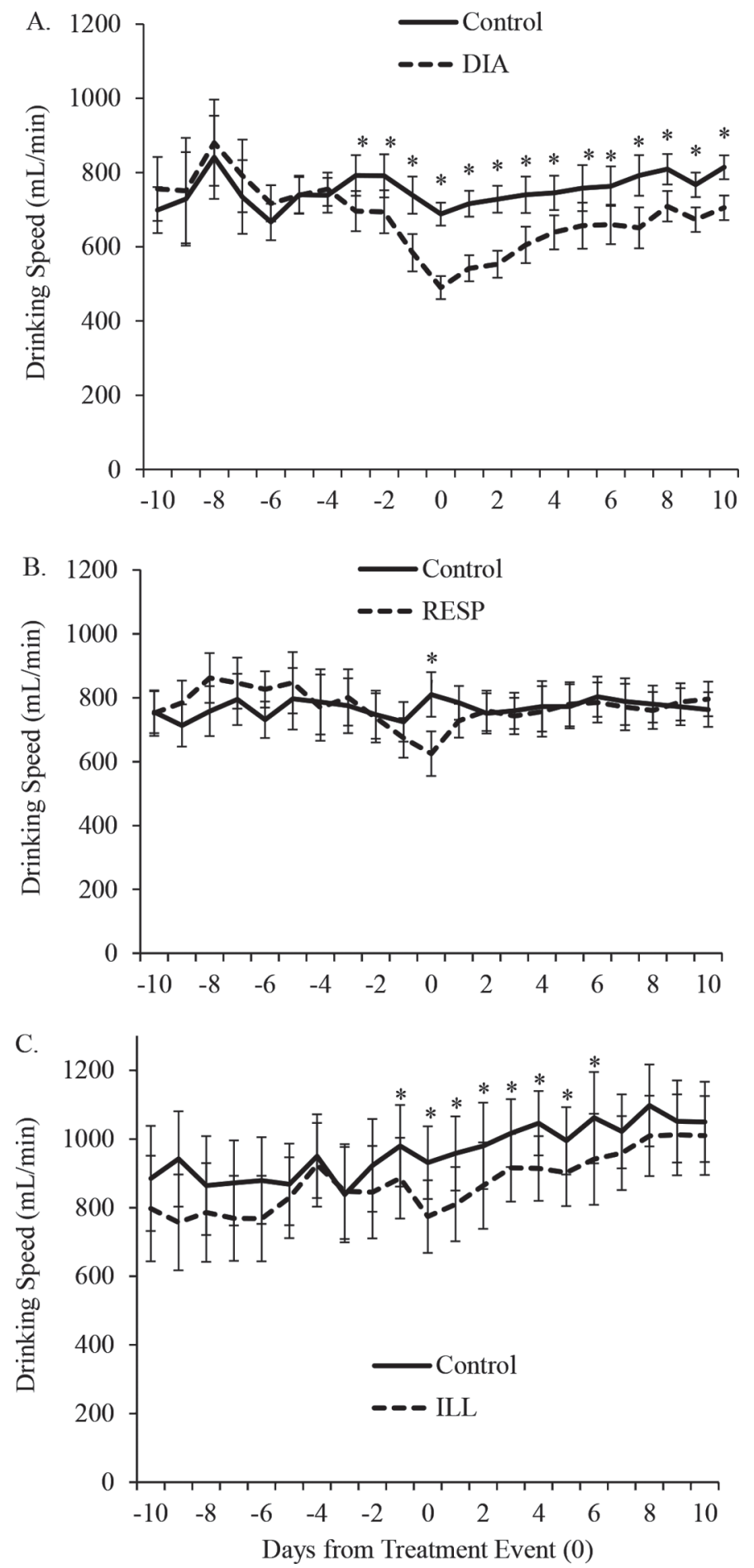

Figure 2. Results from a disease-stratified mixed model exploring the relationship between disease status and drinking speed $(\mathrm{mL} /$ min) over the $20 \mathrm{~d}$ surrounding a treatment event for matched pairs of sick and healthy (control) calves. Reported are adjusted means and standard errors for (A) diarrheal (DIA) disease ( $\mathrm{n}=97$ pairs); (B) respiratory (RESP) disease $(\mathrm{n}=53$ pairs); and $(\mathrm{C})$ ill thrift (ILL; $\mathrm{n}=$ 26 pairs). ${ }^{*} P<0.05$.
-3 , and then from $\mathrm{d}-1$ to 1 , and calves with DIA had significantly fewer visits to the feeder without a milk meal from $d-2$ until the end of the observation period (results not shown).

Milk Consumption. Over the $20 \mathrm{~d}$ surrounding a treatment event, treated calves drank an average of 0.6 $\pm 0.1 \mathrm{~L}(P<0.001)$ less milk per day than healthy calves, after controlling for the effect of calf age, group size, diagnosis, month, repeated measurements on calf, and the random effect of farm. When considering all diseases, the results of the daily stratified model showed that sick calves drank significantly less milk d 7, 5, and 2 before a treatment event, and this effect persisted for $10 \mathrm{~d}$ after treatment (Figure 4). On the day of illness detection, sick calves drank $1.2 \pm 0.2 \mathrm{~L} / \mathrm{d}(P<0.0001)$ less than matched healthy calves. Similarly, after stratifying by disease type, calves treated for DIA drank significantly less milk 8 and $2 \mathrm{~d}$ before a treatment event, which persisted through the end of the observation period. However, calves treated for RESP or ILL did not drink significantly different volumes than their matched healthy controls. (Results not shown)

Rewarded Visits. Sick calves visited the feeder for a milk meal $0.2 \pm 0.1$ fewer times per day than a matched healthy calf over the $20 \mathrm{~d}$ surrounding a treatment event after controlling for the effect of calf age, group size, diagnosis, month, and region, and this was not statistically different $(P=0.12)$. Stratification by disease revealed identical results.

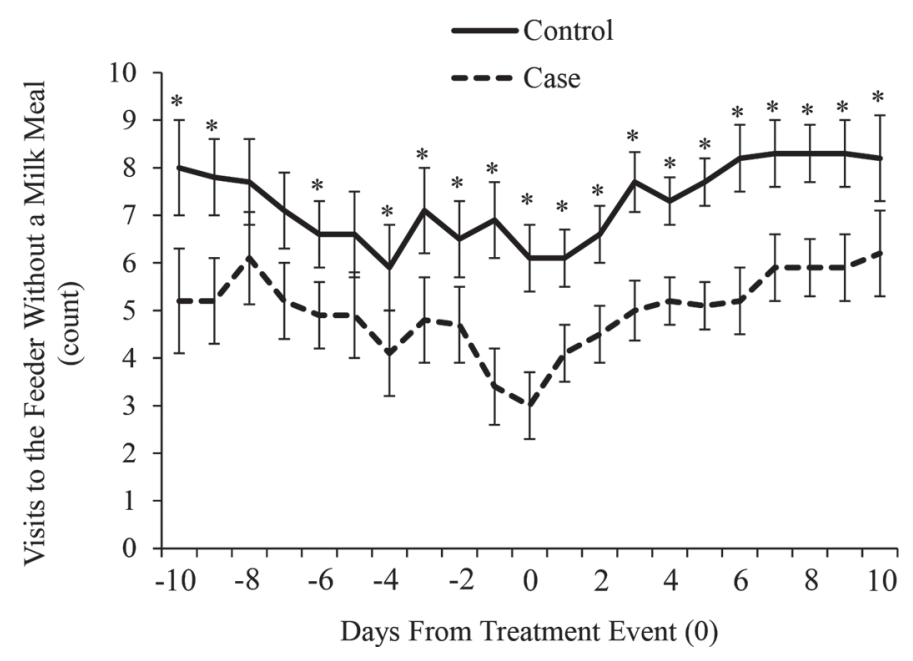

Figure 3. Results of a stratified mixed model describing the relationship between daily average unrewarded visits to the automatic calf feeder and morbidity (all diseases) over the $20 \mathrm{~d}$ surrounding a treatment event for matched pairs of sick (case; $\mathrm{n}=176$ ) and healthy (control; $\mathrm{n}=176$ ) group-housed calves. This model controlled for calf age, group size, disease diagnosis, month, and the random effect of farm. Reported are adjusted means and standard errors. ${ }^{*} P<0.05$. 


\section{DISCUSSION}

Increased morbidity and delays in disease detection are significant challenges for dairy producers who house calves in groups during the preweaning period. Current software algorithms used by automated computer feeder systems may not be timely or sensitive in helping producers to detect sick calves. Management strategies and tools that improve screening and detection of disease are of great importance for the welfare of the calf and the sustainability of these housing and calf-feeding systems. Our prospective observational cohort is the largest field study to date to investigate the association between morbidity and automatically captured feeding behaviors in dairy calves, and gives insight into feeding behavior parameters that will be useful to investigate further as potential predictors or indicators of disease in group-housed preweaned dairy calves.

\section{Calf Management}

Little work to date has focused on describing the management of computer feeders, and these systems can vary greatly based on software settings and producer and technician preference. The average feeding plan in our study included a 10-d background period where calves were manually fed their milk, then, upon entrance to the group pen, an average ramp up of 10 $\mathrm{d}$, a hold period of $30 \mathrm{~d}$, and a ramp down of $13 \mathrm{~d}$, with average milk offered during the hold period of 9.4 $\mathrm{L} / \mathrm{d}$. This is a high level of milk intake, as other studies have reported that the average calf that is allowed ad

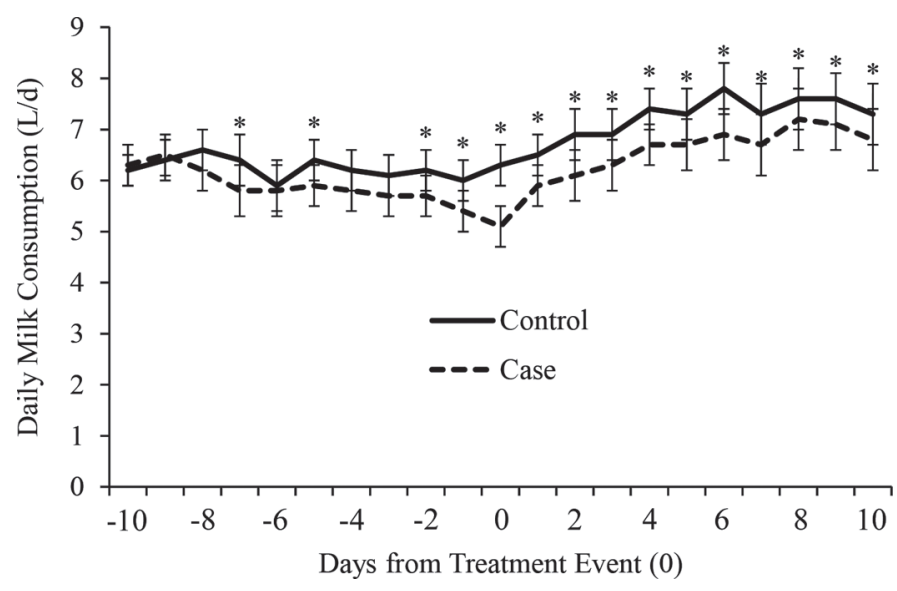

Figure 4. Results of a stratified mixed model describing the relationship between daily average milk consumption $(\mathrm{L} / \mathrm{d})$ and morbidity (all diseases) over the $20 \mathrm{~d}$ surrounding a treatment event for matched pairs of sick (case; $\mathrm{n}=176$ ) and healthy (control; $\mathrm{n}=176$ ) calves. This model controlled for calf age, group size, disease diagnosis, month, and the random effect of farm. Reported are adjusted means and standard errors. ${ }^{*} P<0.05$. libitum milk intake will drink between 9 and $11 \mathrm{~L} / \mathrm{d}$ (Jasper and Weary, 2002; Berberich and Grimm, 2013). This also represents a longer period of total average milk intake $(63 \mathrm{~d})$, which is becoming more common as producers understand the benefits of feeding milk to calves for a longer time period.

\section{Individual Calf Characteristics}

Calves in our study were managed in individual hutches before entrance to the group pen at $9.1 \pm 5$ $\mathrm{d}$ of age. This is later than the $5.1 \pm 3.9 \mathrm{~d}$ reported for calf facilities in the upper Midwest in the United States (Jorgensen, 2016) but within the range of 1 to 2 wk described in Sweden (Svensson et al., 2003). Therefore, our results may not be generalizable to calves that are introduced to the group pen very early, as calves that are introduced early in life have been shown to need more time and assistance to adapt to the feeder (Jensen, 2007), which may affect feeding behaviors. On average, calves in our study gained $0.72 \mathrm{~kg} / \mathrm{d}$, which is comparable to the performance reported in other studies feeding comparable amounts of milk (Appleby et al., 2001; Jasper and Weary, 2002) and sufficient for the doubling of birth weight by $60 \mathrm{~d}$ of life, as is recommended by the industry (Soberon and Van Amburgh, 2013). Treated calves had reduced growth compared with control calves in the matched pair analysis, which is expected for calves experiencing a morbidity event during the preweaning period (Virtala et al., 1996).

\section{Calf Health}

Calves housed in large groups ( $\geq 7$ calves per group) are at an increased risk for morbidity (Svensson and Liberg, 2006). In our study, $63 \%$ of calves had a first treatment event, similar to what has been reported in the literature for other group housing studies, with reported disease incidence ranging from 49 to $78 \%$ (Svensson and Jensen, 2007; Roth et al., 2009). Diarrheal disease remains the most common cause of preweaning morbidity, and represented $50 \%$ of cases treated in our study. Diarrhea incidence reported in the literature in group-housed calves ranges from 19 to 96\% (Svensson and Liberg, 2006; Borderas et al., 2009). The incidence of respiratory disease in our study was $18 \%$, within the range of previously reported incidences of 4 to 31\% (Svensson and Liberg, 2006; Svensson and Jensen, 2007). Of the calves that entered the group feeding pens, $1.14 \%$ died on our 10 study farms. A $16-$ mo longitudinal study of Midwestern calf operations utilizing automatic calf feeders found a higher mortality at $3.85 \%$ per year (Jorgensen, 2016). Our study also represents a lower mortality rate than has been previ- 
ously reported in the United States (USDA-NAHMS, 2016), but it is difficult to compare across studies because of seasonal, regional, and housing differences. We also only selected farms for enrollment if they kept good treatment records, so we may have introduced a selection bias as herd representatives on our farms may have been more skilled (than average) at finding and treating sick animals in a timely manner.

\section{Feeding Behaviors}

Individual calf-feeding behaviors are influenced by many factors, and these influences lead to the large variation that was seen in daily average feeding behaviors in our study. The automatic feeder itself could mechanically influence drinking speed through hose diameter or the size of the nipple opening or nipple type. Though unreported, descriptive analysis of DS by farm supports this hypothesis, though many other variables could influence this difference. We accounted for this by controlling for the random effect of farm in our models. Both rewarded and unrewarded visits to the feeder can be influenced by meal size, total volume offered, and day in the group pen (Jensen, 2009). Total milk offered can also affect feeding behaviors, as limit-fed calves have been shown to visit the feeder $40 \%$ more than calves fed an ad libitum amount (Berberich and Grimm, 2013). Other management factors can also influence feeding behaviors. For example, large group size can cause an increase in URV as calf displacements increase as a function of calf competition for resources (Jensen, 2004). Additionally, mixing calves has been shown to affect CON and total visits to the feeder (O'Driscoll et al., 2006), which could affect these parameters in dynamic pens. Calf-level factors can also influence feeding behaviors, including breed and calf age (Jensen and Holm, 2003). These factors, in combination, contribute to the large variation that we saw in our study in daily average individual calf feeding behaviors. The large numeric difference we observed in daily average DS between sick and healthy calf days has not been described in the literature. Svensson and Jensen (2007) found a nonsignificant difference in drinking speed between sick and health calves; however, these calves were housed in smaller groups (range $=5-10$ per pen) than the calves in the present study. Svensson and Jensen (2007) also found no difference between RV in sick and healthy calves, suggesting that calves will continue to visit the feeder when they are ill, as was observed in our study.

\section{Feeding Behaviors and Disease}

The results of the matched pair analysis show that calves have reduced daily average DS, URV, and CON starting as early as $4 \mathrm{~d}$ before and during a producer identified illness event, but these changes varied by feeding behavior and disease diagnosed. Rewarded visits were not found to be associated with morbidity, suggesting that calves will continue to visit the feeder during an illness event, though they may drink more slowly, drink smaller volumes, and they will not be motivated to visit the feeder more frequently than they have to. Calves change their behavior during an illness event; Cramer and Stanton (2015) showed that calves were less likely to rise when approached by a human when ill. This reluctance to get up could be regulated by infectious and inflammatory mediators, and could explain the decrease in URV to the feeder observed in our study and others (Jensen and Holm, 2003; Svensson and Jensen 2007; Borderas et al., 2009). In our study, calves had significantly fewer URV to the feeder up to 4 d before a treatment event, though the stratified analysis suggests that sick calves had numerically fewer visits than healthy calves over the entire observation period $(-10$ to $10 \mathrm{~d})$. This could be explained by the large proportion of calves with diarrhea, that these calves may be different from healthy calves upon entrance to the group pen, or that a decrease in URV is a stronger indicator of disease than has previously been thought. Drinking speed has not been evaluated previously in a matched pair design in the literature, despite producers' reported use of this parameter as a screening tool to find sick calves in the field. Our work shows that sick calves change their drinking speed up to $3 \mathrm{~d}$ before a diarrheal episode, indicating its utility as a potential indicator of disease onset.

It is possible that differences in disease pathophysiology cause calves to behave differently. This is important to note, as there may be some diseases (i.e., diarrheal disease) that are more easily identified by a change in daily average feeding behaviors than others (i.e., respiratory disease). In our study, diarrheal disease was consistently associated with a change in CON, DS, and URV up to $3 \mathrm{~d}$ before treatment. This same pattern was not observed for calves treated for either RESP or ILL. Though our objective was not to investigate recovery from disease, it is interesting to note that changes in feeding behaviors persisted from between 7 and $10 \mathrm{~d}$ after disease diagnosis. Several possibilities exist for this observation. First, it could simply take calves a significant amount of time to recover from illness. Second, treatments may not be delivered in a timely fashion or are inappropriate for the diagnosis, though review of treatment records does not indicate this. Third, treatment dosage, administration, or duration may not be appropriate to support a rapid recovery by the animal. These questions require further investigation. 
Now that we have a better understanding of which feeding behaviors are more likely to change in advance of a disease event, studies are needed to investigate the utility of using feeding behavior to predict, detect, and treat disease. Maatje et al. (1993) examined DS, CON, RV and URV and deviations from average to identify sick calves and found DS to have the highest sensitivity $(46 \%)$ to screen a sick calf; when combinations of behaviors were explored that sensitivity increased to $77 \%$. However, Maatje et al. (1993) only used a mean deviation percent, which does not take variation into consideration. The results of the present study suggest that CON, DS, and URV are promising early indicators, and may help predict or detect disease in these systems. Future work is needed to investigate these hypotheses.

\section{CONCLUSIONS}

The results of this prospective observational cohort study indicate that sick calves change their feeding behavior during the time leading up to and during an illness event. In a matched pair analysis, treated calves drank more slowly, drank smaller volumes, and visited the feeder fewer times without a milk meal (unrewarded visits) up to $4 \mathrm{~d}$ before they were identified as sick by farm personnel, and this difference persisted for up to $10 \mathrm{~d}$ after diagnosis and treatment. However, these behavioral changes differed by disease; compared with healthy control calves, calves with DIA had the earliest and most consistent changes in feeding behaviors, followed by ILL calves, and finally RESP calves. More work is needed to investigate the utility of using feeding behavior to identify, diagnose, and treat calves in a group-housed setting.

\section{ACKNOWLEDGMENTS}

The authors thank the collaborating dairies for their willingness to participate in this project. The field work in Minnesota was funded by the University of Minnesota, College of Veterinary Medicine Population Systems Signature Program. The Virginia component of this study was funded through the Virginia State Dairymen's Association (Bridgewater, VA) and Land O'Lakes Animal Milk Products (Shoreview, MN). Salary support for Whitney Knauer was provided by USDA grant \#2012-38420-30221.

\section{REFERENCES}

Appleby, M., D. M. Weary, and B. Chua. 2001. Performance and feeding behavior of calves on ad libitum milk from artificial teats. Appl. Anim. Behav. Sci. 74:191-201.
Berberich, N., and H. Grimm. 2013. Effects of two feeding systems on the development of dairy calves. Landtechnik 68:333-338.

Borderas, T. F., A. M. B. de Passille, and J. Rushen. 2008. Behavior of dairy calves after a low dose of bacterial endotoxin. J. Anim. Sci. 86:2920-2927.

Borderas, T. F., J. Rushen, M. A. G. von Keyserlingk, and A. M. B. de Passille. 2009. Automated measurement of changes in feeding behavior of milk-fed calves associated with illness. J. Dairy Sci. 92:4549-4554.

Correa, M. T., C. R. Curtis, H. N. Erb, and M. E. White. 1988. Effect of calfhood morbidity on age at first calving in New York Holstein herds. Prev. Vet. Med. 6:253-262.

Cramer, M. C., and A. L. Stanton. 2015. Associations between health status and the probability of approaching a novel object or stationary human in preweaned group-housed dairy calves. J. Dairy Sci. 98:7298-7308.

De Paula Vieira, A., A. M. de Passille, and D. M. Weary. 2012. Effects of early social environment on behavioral responses of dairy calves to novel events. J. Dairy Sci. 95:5149-5155.

Dohoo, I., W. Martin, and H. Stryhn. 2009. Veterinary Epidemiologic Research. VER, Inc., Charlottetown, Prince Edward Island, Canada.

Hart, B. L. 1988. Biological basis of the behavior of sick animals. Neurosci. Biobehav. Rev. 12:123-137.

Heinrichs, A. J., and B. S. Heinrichs. 2011. A prospective study of calf factors affecting first-lactation and lifetime milk production and age of cows when removed from the herd. J. Dairy Sci. 94:336-341.

Huuskonen, A., and H. Khalili. 2008. Computer-controlled milk replacer feeding strategies for group-reared dairy calves. Livest. Sci. 113:302-306

Jasper, J., and D. M. Weary. 2002. Effects of ad libitum milk intake on dairy calves. J. Dairy Sci. 85:3054-3058.

Jensen, M. B. 2004. Computer-controlled milk feeding of dairy calves: The effects of number of calves per feeder and number of milk portions on use of feeder and social behavior. J. Dairy Sci. 87:34283438 .

Jensen, M. B. 2007. Age at introduction to the group affects dairy calves' use of a computer-controlled milk feeder. Appl. Anim. Behav. Sci. 107:22-31.

Jensen, M. B. 2009. Short communication: Milk meal pattern of dairy calves is affected by computer-controlled milk feeder set-up. J. Dairy Sci. 92:2906-2910.

Jensen, M. B., and L. Holm. 2003. The effect of milk flow rate and milk allowance on feeding related behavior in dairy calves fed by computer controlled milk feeders. Appl. Anim. Behav. Sci. 82:87-100.

Jensen, M. B., L. Munksgaard, L. Mogensen, and C. C. Krohn. 1999. Effects of housing in different social environments on open field and social responses of female dairy calves. Acta. Agric. Scand. 49:113-120.

Johnson, R. W. 2002. The concept of sickness behavior: A brief chronological account of four key discoveries. Vet. Immunol. Immunopathol. 87:443-450.

Jorgensen, M. W. 2016. Dairy calf health and welfare in automated feeding systems in the upper Midwest U.S.A. PhD thesis. Department of Animal Science, University of Minnesota, St. Paul.

Kluger, M. J., and L. K. Vaughn. 1978. Fever and survival in rabbits infected with Pasteurella multocida. J. Physiol. 282:243-251.

Kung, L., S. Demarco, L. N. Siebenson, E. Joyner, G. F. W. Haenlein, and R. M. Morris. 1997. An evaluation of two management systems for rearing calves fed milk replacer. J. Dairy Sci. 80:2529-2533.

Losinger, W. C., and A. J. Heinrichs. 1997. Management practices associated with high mortality among preweaned dairy heifers. J. Dairy Res. 64:1-11.

Maatje, K., J. Verhoeff, W. D. J. Kremer, A. L. M. Cruijsen, and T. S. G. A. M. van den Ingh. 1993. Automated feeding of milk replacer and health control of group-housed veal calves. Vet. Rec. 133:266-270.

McGuirk, S. 2008. Disease management of dairy calves and heifer. Vet. Clin. North Am. Food Anim. Pract. 24:139-153.

Murray, M. J., and A. B. Murray. 1979. Anorexia of infection as a mechanism of host defense. Am. J. Clin. Nutr. 32:593-596. 
O'Driscoll, K., M. A. G. von Keyserlingk, and D. M. Weary. 2006. Effects of mixing on drinking and competitive behavior of dairy calves. J. Dairy Sci. 89:229-233.

Quimby, W. F., B. F. Sowell, J. G. P. Bowman, M. E. Branine, M. E. Hubbert, and H. W. Sherwood. 2001. Application of feeding behaviour to predict morbidity of newly received calves in a commercial feedlot. Can. J. Anim. Sci. 81:315-320.

Roth, B. A., E. Hillman, M. Stauffacher, and N. M. Keil. 2008. Improved weaning reduces cross-sucking and may improve weight gain in dairy calves. Appl. Anim. Behav. Sci. 111:251-261.

Roth, B. A., N. M. Keil, L. Gygax, and E. Hillman. 2009. Influence of weaning method on health status and rumen development in dairy calves. J. Dairy Sci. 92:645-656.

Schaeffer, A. L., N. Cook, S. V. Tessaro, D. Deregt, G. Desroches, P. L. Dubeski, A. K. W. Tong, and D. L. Godson. 2004. Early detection and prediction of infection using infrared thermography. Can. J. Anim. Sci. 84:73-80

Soberon, F., and M. E. Van Amburgh. 2013. The effect of nutrient intake from milk or milk replacer of preweaned dairy calves on lactation milk yield as adults: A meta-analysis of current data. J. Anim. Sci. 91:706-712.

Steenkamer, N. 1982. Alternative housing systems for veal calves, their effect on welfare and performance and their economic feasibility. Pages 226-234 in Welfare and Husbandry of Calves: Current Topics in Veterinary Medicine and Animal Science. J. P. Signoret, ed. Martinus Nijhoff Publishers, Leiden, the Netherlands.
Steiger, M., M. Senn, G. Altreuther, D. Werling, F. Sutter, M. Kruezer and W. Langhans. 1999. Effect of a prolonged low-dose lipopolysaccharide infusion on feed intake and metabolism in heifers. J. Anim. Sci. 77:2523-2532.

Svensson, C., and M. B. Jensen. 2007. Short communication: Identification of diseased calves by use of data from automatic milk feeders. J. Dairy Sci. 90:994-997.

Svensson, C., and P. Liberg. 2006. Effect of group size on health and growth rate of Swedish dairy calves housed in pens with automatic milk-feeders. Prev. Vet. Med. 73:43-53.

Svensson, C., K. Lundborg, U. Emanuelson, and S. O. Olsson. 2003. Morbidity in Swedish dairy calves from birth to 90 days of age and individual calf-level risk factors for infectious diseases. Prev. Vet. Med. 58:179-197.

USDA-NAHMS. 2016. Dairy 2014. Dairy cattle management practices in the United States, 2014. Accessed October 26, 2016. https:// www.aphis.usda.gov/animal_health/nahms/dairy/downloads/ dairy14/Dairy14_dr_PartI.pdf.

Virtala, A. M., G. D. Mechor, Y. T. Grohn, and H. N. Erb. 1996. The effect of calfhood diseases on growth of female dairy calves during the first 3 months of life in New York state. J. Dairy Sci. 79:1040-1049.

Waltner-Toews, D., S. W. Martin, and A. H. Meek. 1986. The effect of early calfhood health status on survivorship and age at first calving. Can. J. Vet. Res. 50:314-317. 